\title{
Curcumol inhibits the malignant progression of prostate cancer and regulates the PDK1/AKT/mTOR pathway by targeting miR-9
}

\author{
WEN SHENG ${ }^{1 *}$, WENJING XU ${ }^{2 *}$, JIN DING $^{3}$, LING LI $^{4}$, XUJUN YOU $^{3}$, YONGRONG WU $^{1}$ and QINGHU HE $^{1}$ \\ ${ }^{1}$ Andrology Laboratory, Hunan University of Chinese Medicine, Changsha, Hunan 410208; \\ ${ }^{2}$ Dermatology Department, The First Hospital of Hunan University of Chinese Medicine, Changsha, Hunan 410021; \\ ${ }^{3}$ Andrology Clinic, Shenzhen Baoan Hospital of Traditional Chinese Medicine, Shenzhen, Guangdong 518133; \\ ${ }^{4}$ Medical Basic Teaching Experiment Center, Hunan University of Chinese Medicine, Changsha, Hunan 410208, P.R. China
}

Received April 9, 2021; Accepted August 12, 2021

DOI: $10.3892 /$ or.2021.8197

\begin{abstract}
Curcumol has been reported to exert anti-tumor activity, but its intrinsic molecular mechanism in prostate cancer remains to be elucidated. The present study aimed to analyze the effect of curcumol on prostate cancer and identify its possible internal regulatory pathway using in vitro cell culture and in vivo tumor model experiments. The cytotoxicity of curcumol was detected using a Cell Counting Kit-8 assay and it was found that curcumol had no obvious toxicity or side effects on RWPE-1 cells. Wound healing, Transwell and flow cytometry assays demonstrated that curcumol could affect the activity of PC3 cells. The luciferase reporter assay also indicated that microRNA (miR)-9 could directly target pyruvate dehydrogenase kinase 1 (PDK1). After PC3 cells were transfected with miR-9 inhibitor or treated with curcumol, the expression levels of the PDK1/AKT/mTOR signaling pathway-related proteins [PDK1, phosphorylated (p)-AKT and p-mTOR] were increased or decreased, respectively. Next, the prostate cancer cell xenograft model was established. Tumor size and the expression levels of PDK1/AKT/mTOR signaling pathway-related factors were altered following treatment with curcumol. The in vitro and in vivo experiments collectively demonstrated that curcumol could inhibit the PDK1/AKT/mTOR signaling pathway by upregulating the expression level of miR-9. The present study found that curcumol regulates the PDK1/AKT/mTOR signaling pathway via miR-9 and affects the development of prostate cancer. These findings could provide a possible scientific insight for research into treatments for prostate cancer.
\end{abstract}

Correspondence to: Dr Qinghu He, Andrology Laboratory, Hunan University of Chinese Medicine, 300 Xueshi Road, Yuelu, Changsha, Hunan 410208, P.R. China

E-mail: qinghu_he3418@hnucm.edu.cn

*Contributed equally

Key words: curcumol, prostate cancer, microRNA-9, pyruvate dehydrogenase kinase $1 / \mathrm{AKT} / \mathrm{mTOR}$ pathway

\section{Introduction}

Prostate cancer is one of the major causes of increased morbidity and mortality worldwide. It is also the most commonly diagnosed type of cancer among men (1). Currently, the main treatments for prostate cancer are surgery, radiation and chemotherapy. Despite improvements in traditional surgical and radiotherapy techniques, the quality of life of patients with prostate cancer remains poor following treatment (2). At present, immunotherapy remains under development and a large number of future clinical trials are required to evaluate its true therapeutic potential (3). Currently androgen blockers are the main therapeutic agents (4). A previous study reported that the long-term use of the novel androgen receptor antagonists can lead to the initiation of drug resistance mechanisms (5). Therefore, the development of additional drug candidates for the treatment of prostate cancer is particularly important.

Curcumol is a monomer compound isolated from the Rhizome curcumae, which possesses anti-inflammatory, anti-oxidation and anti-tumor pharmacological activities (6). Previously, the aromatization of curcumol derivatives has been reported to exert anti-tumor effects (7). In addition, curcumol has a therapeutic effect on liver fibrosis (8), liver cancer (9), bladder cancer (10) and lung adenocarcinoma (11). Some researchers have also observed that curcumol can not only inhibit the epithelial-to-mesenchymal transition (EMT) of triple-negative breast cancer (12) but also enhance the drug sensitivity of cancer cells (13). Thus, it has been hypothesized that curcumol is a promising anti-tumor drug. However, the role of curcumol in the treatment of prostate cancer remains to be elucidated.

Therefore, the present study aimed to screen curcumol sensitive prostate cancer cells by verifying the pharmacological activity of curcumol. At the same time, the internal regulatory pathway of curcumol on prostate cancer was further investigated via in vitro cell experiments and in vivo animal experiments. The present findings may provide reliable scientific information for the treatment of prostate cancer with curcumol.

\section{Materials and methods}

Cell culture and treatment. Prostate cancer cell lines (PC3, DU145, LNCaP) and normal prostate cells (RWPE-1) were 
purchased from Shanghai Zhongqiao Xinzhou Biotechnology Co., Ltd.PC3, DU145, LNCaP and RWPE-1 cells were cultured in F-12 (Sigma-Aldrich; Merck KGaA), MEM (Shanghai Zhongqiao Xinzhou Biotechnology Co., Ltd.), RPMI-1640 (Shanghai Zhongqiao Xinzhou Biotechnology Co., Ltd.) and special medium ( $1 \%$ keratinocyte growth factor) (Shanghai Zhongqiao Xinzhou Biotechnology Co., Ltd.) respectively, which were supplemented with $10 \%$ FBS (Gibco; Thermo Fisher Scientific, Inc.) and $1 \%$ penicillin-streptomycin solution (Beyotime Institute of Biotechnology), at $37^{\circ} \mathrm{C}$ with $5 \% \mathrm{CO}_{2}$ and saturated humidity.

In order to screen the cell types and concentration of curcumol (cat. no. B20342, Shanghai YuanYe Biotechnology Co., Ltd.), four types of cells (PC3, DU145, LNCaP and RWPE-1 cells) in the logarithmic growth phase were selected. Curcumol was dissolved into the original solution with a concentration of $10 \mathrm{mg} / \mathrm{ml}$ using absolute ethanol and diluted using medium (F-12, MEM, RPMI-1640, or special medium) (14). The specific groups were as follows: $0 \mu \mathrm{g} / \mathrm{ml}$ (treated with $0 \mu \mathrm{g} / \mathrm{ml}$ curcumol), $25 \mu \mathrm{g} / \mathrm{ml}$ (treated with $25 \mu \mathrm{g} / \mathrm{ml}$ curcumol), $50 \mu \mathrm{g} / \mathrm{ml}$ (treated with $50 \mu \mathrm{g} / \mathrm{ml}$ curcumol) and $100 \mu \mathrm{g} / \mathrm{ml}$ (treated with $100 \mu \mathrm{g} / \mathrm{ml}$ curcumol). The cells were treated with these different concentrations of curcumol for $24 \mathrm{~h}$ at $37^{\circ} \mathrm{C}$.

Based on curcumol concentration screening results, it was found that the comparison between different types of cells had significant statistical significance in the $50 \mu \mathrm{g} / \mathrm{ml}$ group. Therefore, a concentration of $50 \mu \mathrm{g} / \mathrm{ml}$ was chosen. The following groups were established: Control group (treated with the same concentration of absolute ethanol and medium) and a Curcumol group (treated with $50 \mu \mathrm{g} / \mathrm{ml}$ curcumol). The prepared cells were used in the subsequent experiments.

Cell transfection and treatment. To investigate the effects of curcumol and miR-9 on PC3 cells, cells in the logarithmic growth phase were divided into the following groups: Control group (blank control group), negative control (NC) group (transfected with NC inhibitor), a miR-9 inhibitor group (transfected with miR-9 inhibitor), Curcumol group (treated with $50 \mu \mathrm{g} / \mathrm{ml}$ curcumol $+\mathrm{NC}$ ) and miR-9 inhibitor + curcumol group (treated with miR-9 inhibitor $+50 \mu \mathrm{g} / \mathrm{ml}$ curcumol).

For verify the transfection efficiency of miR-9 mimics, cells were divided into the following groups: NC group (transfected with NC mimics) and miR-9 mimics group (transfected with miR-9 mimics).

The NC inhibitor, miR-9 inhibitor, NC mimics, and miR-9 mimics were purchased from HonorGene. Lipofectamine ${ }^{\circledR} 2000$ (5 $\mu \mathrm{l}$; Thermo Fisher Scientific, Inc.) was used for $5 \mu \mathrm{l} \mathrm{miR-9}$ inhibitor (NC inhibitor) or miR-9 mimics (NC mimics) transfection into cells at $37^{\circ} \mathrm{C}$ for $6 \mathrm{~h}$. The concentration of miR-9 inhibitor, NC inhibitor, miR-9 mimics and NC mimics was $50 \mathrm{nM}$. After transfection for $48 \mathrm{~h}$, the curcumol group and miR-9 inhibitor + curcumol group were treated with $50 \mu \mathrm{g} / \mathrm{ml}$ curcumol for $24 \mathrm{~h}$ at $37^{\circ} \mathrm{C}$. The prepared cells were immediately used in the subsequent experiments. The sequence of has-miR-9 inhibitor was 5'-UCAUACAGCUAGAUAACC AAAGA-3'. The sequence of NC inhibitor was 5'-CAGUAC UUUUGUGUAGUACAA-3'. The sequence of miR-9 mimics was 5'-AUAAAGCUAGAUAACCGAAAGU-3'. The sequence of NC mimics was 5'-UUCUCCGAACGUGUCACGU-3'.
Cell Counting Kit (CCK)-8 assay. Cell Counting Kit-8 (cat. no. NU679; Dojindo Molecular Technologies, Inc.) was used according to the manufacturer's instructions. The prepared cells were digested and counted. Cells were inoculated in 96-well plates at a density of $1 \times 10^{4}$ cells/well. In total, five duplicate wells were used. After cells adhered, they were grouped as aforementioned. Drug-containing medium was removed. The prepared CCK-8 solution (final concentration $10 \mu \mathrm{l} /$ well) was added. After incubation at $37^{\circ} \mathrm{C}$ with $5 \% \mathrm{CO}_{2}$ for $4 \mathrm{~h}$, the absorbance was measured at $450 \mathrm{~nm}$ using a BioTek plate analyzer (BioTek Instruments, Inc.).

Wound healing assay. PC 3 cells in the logarithmic growth phase were selected and divided into a Control group (blank control group) and a Curcumol group (50 $\mu \mathrm{g} / \mathrm{ml}$ curcumol group). In total, three repeated experiments were set in each group. The 6-well plates were evenly drawn with horizontal lines. Trypsin was utilized to digest PC 3 cells. Following cell counting, $\sim 5 \times 10^{5}$ cells were added to each well. After the cells were added onto the plate, a $100 \mu l$ pipette tip was used to create a scratch perpendicular to the horizontal line previously drawn. Sterile PBS was used to wash the cells and it was repeated three times. Serum-free DMEM was added. The following time points were selected: 0,24 and $48 \mathrm{~h}$ and three fields were selected for each time point. The cells were observed under a light microscope at magnification, $\mathrm{x} 100$. The culture conditions were $37^{\circ} \mathrm{C}$ and $5 \% \mathrm{CO}_{2}$.

Transwell assay. For the cell invasion assay, Matrigel, Transwell plates (24-well, $8.0 \mu \mathrm{m}$ pore membranes) and sterile hypodermic needles were pre-cooled overnight at $4^{\circ} \mathrm{C}$ in advance. Each well was added with $60 \mu \mathrm{l}$ diluted matrix gel. After incubation at $37^{\circ} \mathrm{C}$ for $30 \mathrm{~min}$, the supernatant was removed. Then, $500 \mu 1$ 10\% FBS-complete medium was placed in the lower chamber. Trypsin was utilized to digest cells. Cells were resuspended to $2 \times 10^{6}$ cells $/ \mathrm{ml}$ on a serum-free medium and $100 \mu \mathrm{l}$ cells were added to each well. After incubation at $37^{\circ} \mathrm{C}$ for $48 \mathrm{~h}$, the upper chamber was removed and washed with PBS. Then, $4 \%$ paraformaldehyde was used for fixation at room temperature for $20 \mathrm{~min}$ and $0.1 \%$ crystal violet was applied for staining at room temperature for $5 \mathrm{~min}$. A light microscope was used for observation, with three fields of view at a magnification, $x 100$. The cavity was decolorized in $500 \mu 110 \%$ acetic acid solution. An enzyme plate analyzer was used to determine the optical density (OD) value at $550 \mathrm{~nm}$, repeated three times.

For the cell migration assay, $500 \mu 110 \%$ FBS complete medium (Gibco; Thermo Fisher Scientific, Inc.) was placed in the lower layer of the chamber. Each well was added with $100 \mu \mathrm{l}$ cells $\left(1 \times 10^{6}\right.$ cells $\left./ \mathrm{ml}\right)$. After incubation at $37^{\circ} \mathrm{C}$ for $48 \mathrm{~h}$, the upper chamber was removed and washed with PBS. Methanol and acetone were prepared to form a stationary solution (equal volume mix). After being fixed at room temperature for $20 \mathrm{~min}$ by mixing methanol and acetone into a fixed solution, the cells were stained with $0.1 \%$ crystal violet at room temperature for $5 \mathrm{~min}$. A light microscope was used for observation, with three fields of view at magnification, $\mathrm{x} 100$. Then, $500 \mu \mathrm{l} 10 \%$ acetic acid solution was used for decolorization. A microplate analyzer was applied to determine the OD value at $550 \mathrm{~nm}$, repeated three times. 
Flow cytometry. The prepared PC3 cells were removed and digested with trypsin (without EDTA). PBS was used to wash the cells and then $1-5 \times 10^{5}$ cells were collected. The following steps were performed according to the manufacturer's instructions of the Annexin V-FITC cell apoptosis detection kit (cat. no. KGA108; Nanjing KeyGen Biotech Co., Ltd.). In total, $500 \mu \mathrm{l}$ Binding buffer was added to suspend the cells. Then, $5 \mu \mathrm{l}$ Annexin V-FITC and $5 \mu \mathrm{l}$ PI were added successively and mixed. The reaction was performed at room temperature in the dark for $10 \mathrm{~min}$. A flow cytometer (A00-1-1102; Beckman Coulter, Inc.) was used for observational detection. The apoptotic rate was calculated (the percentage of early + late apoptotic cells).

Western blotting. Briefly, $200 \mu 1$ RIPA lysate (cat. no. P0013B; Beyotime Institute of Biotechnology) was used to extract total protein from $0.025 \mathrm{~g}$ tissues or $2 \times 10^{6}$ cells. After lysis of tissue homogenate or cell suspension on ice for $10 \mathrm{~min}$, the supernatant was obtained by centrifugation with $13,280 \mathrm{x} \mathrm{g}$ at $4^{\circ} \mathrm{C}$ for $15 \mathrm{~min}$. A BCA Protein Assay Kit (cat. no. P0012S; Beyotime Institute of Biotechnology) was used to determine protein concentration according to the manufacturer's instructions. The mass of protein loaded per lane was $\sim 20 \mu \mathrm{g}$. $10 \%$ polypropylene gel was configured. Polyacrylamide gel electrophoresis was performed with a constant voltage of $75 \mathrm{~V}$ at room temperature. The protein was transferred to the nitrocellulose membrane at a constant current of $300 \mathrm{~mA}$. Next, $5 \%$ skimmed milk was used to block the membrane at $4^{\circ} \mathrm{C}$ overnight. The primary antibody was incubated for $90 \mathrm{~min}$ at room temperature. The following primary antibodies were used: PDK1 (cat. no. ab202468; Abcam; dilution 1:2,000), total AKT (cat. no. ab179463; Abcam; dilution 1:10,000), phosphorylated (p)-AKT (cat. no. ab131443; Abcam; dilution 1:500), total mTOR (cat. no. ab32028; Abcam; dilution 1:1,000), p-mTOR (cat. no. ab109268; Abcam; dilution 1:1,000) and $\beta$-actin (cat. no. 66009-1-Ig; ProteinTech Group, Inc.; dilution 1:5,000). The secondary antibodies HRP goat anti-mouse IgG (cat. no. SA00001-1; ProteinTech Group, Inc.; dilution 1:5,000) and HRP goat anti-rabbit IgG (cat. no. SA00001-2; ProteinTech Group, Inc.; dilution 1:6,000) were incubated at room temperature for 90 min. ECL solution (cat. no. K-12045-D50; Advansta, Inc.) was used for visualization in a darkroom. Quantity One software (version 4.6.2; Bio-Rad Laboratories, Inc.) was used to analyze the protein expression.

$R N A$ isolation and reverse transcription-quantitative PCR $(R T-q P C R)$. When the cell density reached $80 \%$, total RNA was extracted using TRIzol ${ }^{\circledR}$ (Thermo Fisher Scientific, Inc.) according to the manufacturer's protocol. Briefly, the RNA concentration was measured with an ultraviolet spectrophotometer. The mixture was incubated at $50^{\circ} \mathrm{C}$ for $50 \mathrm{~min}$, followed by $85^{\circ} \mathrm{C}$ for $5 \mathrm{~min}$ and then cooled on ice. HiFiScript cDNA Synthesis kit (cat. no. CW2569M; CWBIO) and SYBR-Green PCR Master Mix (cat. no. CW2601S; CWBIO) were used according to the manufacturer's protocols. A $30 \mu$ lamplification system was used, with three replicates and 40 cycles. A two-step method was used for amplification, which included: Extending at $95^{\circ} \mathrm{C}$ for $15 \mathrm{~min}$, denaturing at $95^{\circ} \mathrm{C}$ for $15 \mathrm{sec}$, and annealing at $60^{\circ} \mathrm{C}$ for $30 \mathrm{sec}$. The $2^{-\Delta \Delta \mathrm{Cq}}$ value (15) was utilized to reflect the sample gene expression levels relative to the ratio of the control sample. The primer sequences were as follows: H-U6 forward (F), 5'-CTCGCTTCGGCAGCACA-3' and reverse (R), 5'-AACGCTTCACGAATTTGCGT-3', product length 125 bp; hsa-miR-9, 5'-CATTATTACTTTTGGTACGCG-3'; H-actin F, 5'-ACCCTGAAGTACCCCATCGAG-3' and R, 5'-AGCACAGCCTGGATAGCAAC-3', product length $224 \mathrm{bp}$; and H-PDK1 F, 5'-CTTTCTGTCCCCACCGCACA-3' and R, 5'-GCAGAAGCCTCCAGAAACTCACA-3', product length $236 \mathrm{bp}$. These experiments were repeated three times.

Dual luciferase reporter gene assay. The potential binding sites between miR-9 and PDK1 were predicted using TargetScan online software (http://www.targetscan.org/vert_72/). After the cells were transfected with NC mimics and miR-9 mimics, the expression of miR-9 was measured for transfection efficiency. Cells were divided into the wild-type (wt)-PDK1 + $\mathrm{NC}$ mimics group (wt-PDK1 + NC), the wt-PDK1 + miR-9 mimics group (wt-PDK1 + miR-9 mimics), the mutant (Mut)-PDK1 + NC mimics group (Mut-PDK1 + NC) and the Mut-PDK1 + miR-9 mimics group (Mut-PDK1 + miR-9 mimics). pHG-MirTarget-WT PDK1-3U, pHG-MirTarget-mut PDK1-3U, miR-9 mimics, NC mimics and 293A cells were purchased from HonorGene. According to the instructions of the Dual-Luciferase Reporter assay system (cat. no. E1910; Promega Corporation), 1XPLB lysis buffer, LAR II and Stop\&Glo buffer were prepared. After transfection for $48 \mathrm{~h}$, the luciferase activity was determined with a GloMax20/20 chemiluminescence detector (Promega Corporation).

Animal model. A total of $30 \mathrm{BALB} / \mathrm{C}$ male nude mice (age, 6 weeks; weight, 13 15 g) were purchased from the SLAC Laboratory. Mice were housed with conditions of $22-24^{\circ} \mathrm{C}$, $12 \mathrm{~h}$ light/dark cycle and $40-60 \%$ relative humidity. The feeding conditions of mice were as described in the previous literature (16). After adaptive feeding for 1 week, the mice were randomly divided into five groups (6 mice in each group): A Control group, an NC group, a miR-9 inhibitor group, a Curcumol group and a miR-9 inhibitor + curcumol group. PC3 cells were transfected with NC inhibitor and miR-9 inhibitor as aforementioned. The mice were subcutaneously injected with $5 \times 10^{6}$ transfected cells. When tumor growth reached $100 \mathrm{~mm}^{3}$, the curcumol administration group received curcumol $(20 \mathrm{mg} / \mathrm{kg})$ peritoneal injection every 2 days $(13,17)$. The tumor was measured twice a week. The tumor volume was calculated as length $\mathrm{x}$ width ${ }^{2} \mathrm{x} 0.5$. When the maximum tumor volume reached $2,000 \mathrm{~mm}^{3}$, the mice were sacrificed via an intraperitoneal injection of pentobarbital sodium $(150 \mathrm{mg} / \mathrm{kg})$. The tumor was removed to prepare for further experiments.

All of the experiments were conducted in accordance with the recommendation and approval of the Animal Welfare Committee of Hunan University of Chinese Medicine (approval no. 2019-0019).

Immunohistochemistry. The tissues were sectioned at $3 \mu \mathrm{m}$ and fixed with $4 \%$ paraformaldehyde at room temperature for $24 \mathrm{~h}$. The tumor tissue was dewaxed.

After EDTA buffer was boiled, the slices were immersed in a boiling water bath for $22 \mathrm{~min}$. Endogenous peroxidase was inactivated with $1 \%$ periodate acid at room temperature for 10 min. Diluted Ki67 (cat. no. ab15580; Rabbit; Abcam) 
with dilution 1:100 was added and it was incubated overnight at $4^{\circ} \mathrm{C}$. The ready-to-use type of secondary antibody (cat. no. PV-9001; OriGene Technologies, Inc.) was added and incubated at $37^{\circ} \mathrm{C}$ for $30 \mathrm{~min}$. After DAB color development at room temperature for $\sim 10 \mathrm{sec}$, the nuclei were stained at room temperature for $1 \mathrm{~min}$. The sections were sealed using neutral resin and observed under a light microscope (BA210; Motic; magnification, $\mathrm{x} 400)$.

Statistical analysis. SPSS 25.0 software (IBM Corp.) and GraphPad 8.0 (GraphPad Software, Inc.) were used for statistical analysis and the measurement data are presented as the mean \pm standard deviation. Unpaired t-test, one-way ANOVA and two-way ANOVA analysis were used. Tukey's multiple and Sidak's multiple comparisons tests were employed. $\mathrm{P}<0.05$ was considered to indicate a statistically significant difference.

\section{Results}

Curcumol cytotoxicity assay and screening of sensitive cells. To test the cytotoxicity of curcumol and drug sensitivity of prostate cancer cells, PC3, DU145, LNCaP and RWPE-1 cells were treated with different concentrations of curcumol $(0,25,50$ and $100 \mu \mathrm{g} / \mathrm{ml})$. The CCK-8 results demonstrated that curcumol had no significant effect on the proliferation of RWPE-1 cells. Compared with DU145 and LNCaP cells, PC3 cells were the most sensitive to curcumol (Fig. 1). In the $50 \mu \mathrm{g} / \mathrm{ml}$ group, the comparison between different types of cells had significant statistical significance. Thus, PC3 cells and $50 \mu \mathrm{g} / \mathrm{ml}$ curcumol were selected for subsequent experiments.

Curcumol inhibits the development of PC3 cells and regulates the PDK1/AKT/mTOR signaling pathway. Next, the effect of curcumol on PC3 cells was examined. The wound healing assay results revealed that the migration of PC3 cells in the curcumol group was significantly lower compared with the control group (Fig. 2A). Transwell (Fig. 2B) and flow cytometry (Fig. 2C) assays were conducted to detect the invasion and apoptosis of PC3 cells. The results indicated that curcumol inhibited the invasive activity of PC3 cells and increased their apoptosis rate. Next, the PDK1/AKT/mTOR signaling pathway was examined at the protein expression level. The results demonstrated that curcumol could decrease the expression level of PDK1. In addition, curcumol inhibited the phosphorylation levels of AKT and mTOR (Fig. 2D).

miR-9 targets PDK1. The previous study has reported that curcumol can regulate the expression level of miR-9 (17). The RT-qPCR results suggested that curcumol could upregulate the expression level of miR-9 (Fig. 3A). Following treatment with curcumol, the expression of miR-9 was significantly different in the PC3 cells (Fig. 3C). Following treatment with $50 \mu \mathrm{g} / \mathrm{ml}$ curcumol, the expression of miR-9 was upregulated in three prostate cancer cell lines and the difference of miR-9 expression was most obvious in PC3 cells. PC3 cells were treated with different concentrations of curcumol $(0,25,50$ and $100 \mu \mathrm{g} / \mathrm{ml})$. The expressions of miR-9 increased with the increase of curcumol concentration (Fig. 3B). This suggested that curcumol could promote the expression of miR-9. No significant difference was observed in the level of miR-9

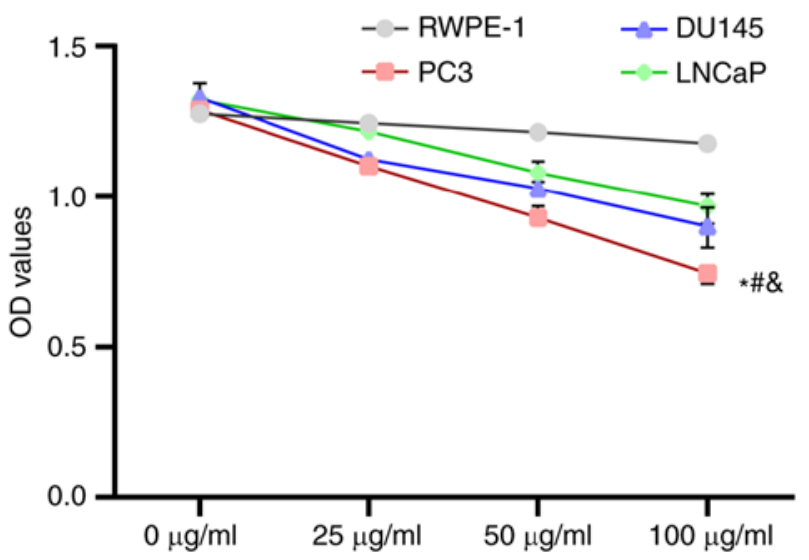

Figure 1. Curcumol cytotoxicity assay and screening of sensitive cells. Following treatment with different concentrations of curcumol $(0,25,50$ and $100 \mu \mathrm{g} / \mathrm{ml}$ ) for $24 \mathrm{~h}$, the cell activity was determined using a Cell Counting Kit- 8 assay. Two-way ANOVA analysis was used. " $\mathrm{P}<0.05$ vs. RWPE-1 cells; ${ }^{\#} \mathrm{P}<0.05$ vs. DU145; ${ }^{\circledR} \mathrm{P}<0.05$ vs. LNCaP cells. OD, optical density.

between the $50 \mu \mathrm{g} / \mathrm{ml}$ group and $100 \mu \mathrm{g} / \mathrm{ml}$ groups. Therefore, $50 \mu \mathrm{g} / \mathrm{ml}$ curcumol was used in the subsequent experiments. After the cells were transfected with NC mimics and miR-9 mimics, the expression of miR-9 was measured for transfection efficiency (Fig. 3D). Based on the TargetScan online software prediction, it was identified that miR-9 might have a direct targeting relationship with PDK1 (Fig. 3E). Therefore, a luciferase reporter assay was utilized to verify the relationship between miR-9 and PDK1. The results revealed that miR-9 could directly target PDK1 (Fig. 3F).

Curcumol regulates the PDK1/AKT/mTOR signaling pathway and affects the activity of PC3 cells via miR-9. To determine whether the regulation of the PDK1/AKT/mTOR signaling pathway by curcumol was mediated by regulating the expression of miR-9, PC3 cells were transfected with miR-9 inhibitor and treated with curcumol. The successful transfection of miR-9 was verified via RT-qPCR (Fig. 4A). It was found that the expression level of PDK1 in the miR-9 inhibitor group was significantly higher compared with that in the control and NC groups. Compared with the miR-9 inhibitor group, the expression level of PDK1 in the miR-9 inhibitor + Curcumol group was significantly decreased (Fig. 4B). This suggested that curcumol could affect the expression of PDK1 via miR-9. The results at the protein level also indicated that curcumol could regulate the PDK1/AKT/mTOR signaling pathway via miR-9 (Fig. 4C). In addition, the experimental results of CCK-8 (Fig. 5A), Transwell (Fig. 5B and C) and flow cytometry (Fig. 5D) assays further indicated that curcumol could affect the activity of PC3 cells via miR-9.

Curcumol inhibits tumor growth in mice. In order to evaluate the effect of curcumol on tumor formation in nude mice, relevant animal models were constructed and treated with curcumol. Tumor volume was measured at different time points in vivo (Fig. 6A). The results demonstrated that curcumol significantly inhibited tumor growth. Compared with the curcumol group, the tumor volume of the miR-9 inhibitor + curcumol group was significantly increased. It was hypothesized that curcumol inhibited tumor growth via miR-9. Following removal, the 
A

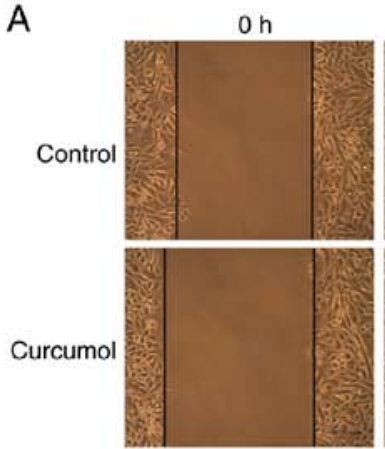

B

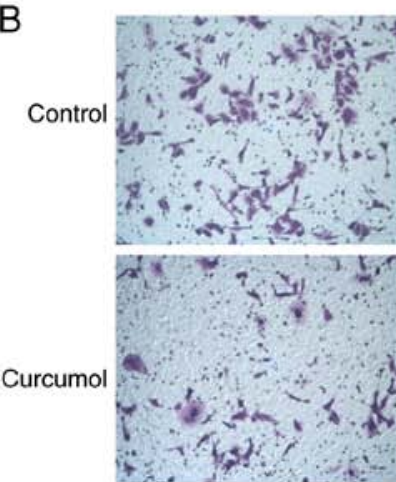

D

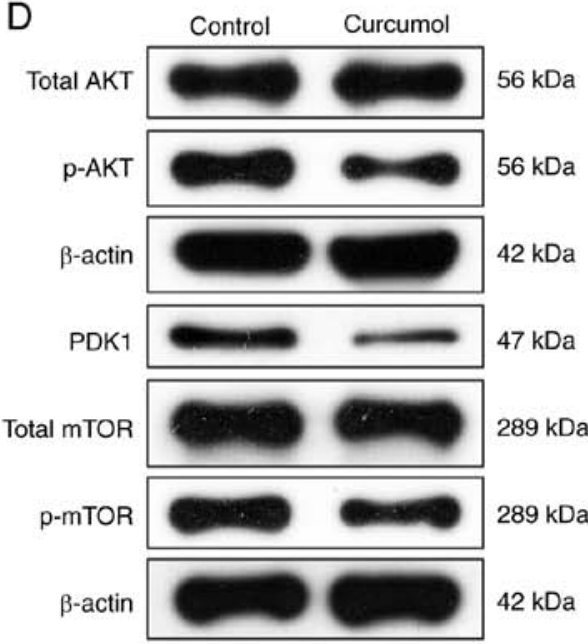

$24 \mathrm{~h}$
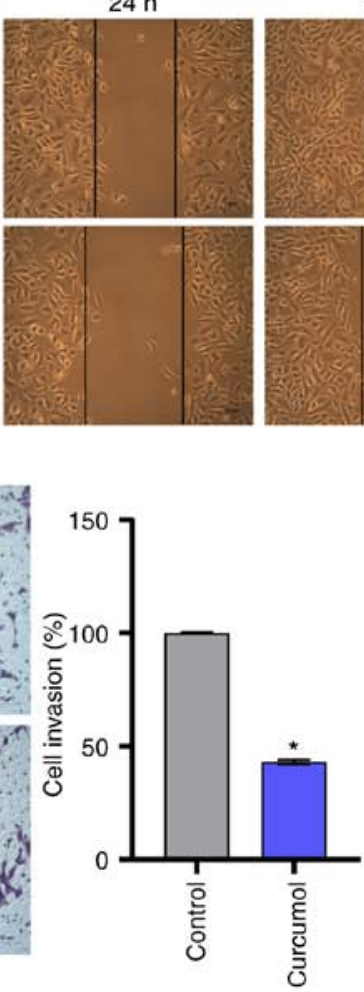

$48 \mathrm{~h}$

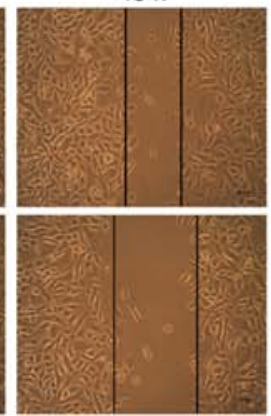

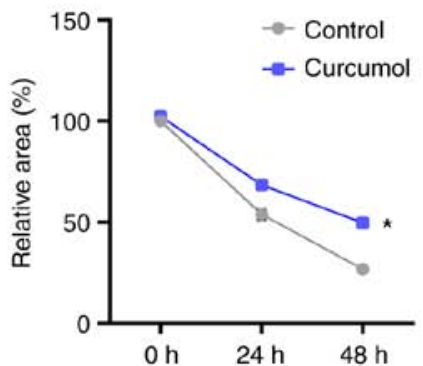

C
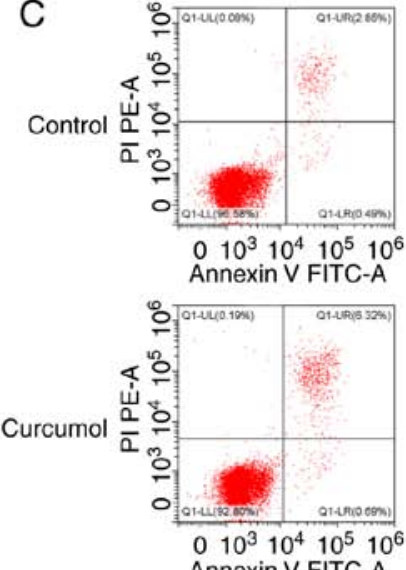

Annexin V FITC-A
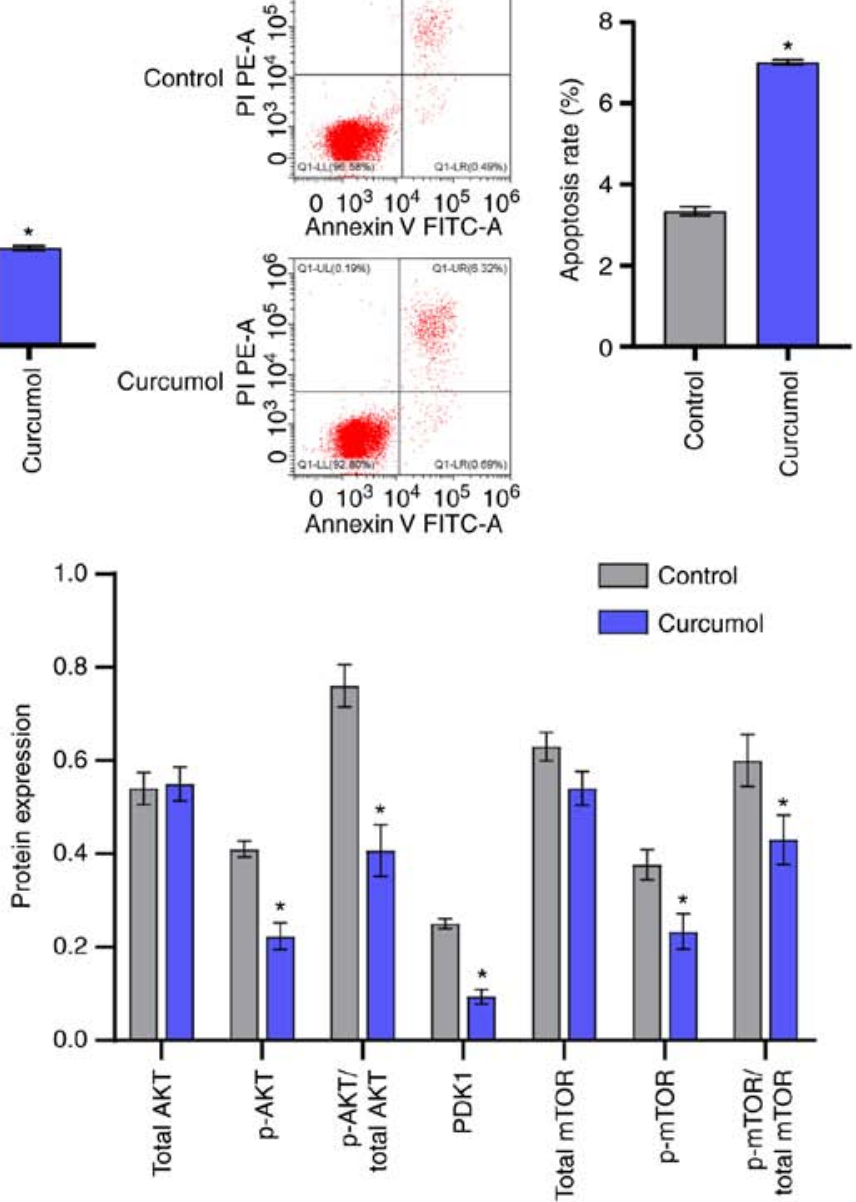

$\square$ Curcumol

Figure 2. Curcumol regulates the PDK1/AKT/mTOR signaling pathway and inhibits the activity of PC3 cells. (A) Wound healing assay results showing cell migration (magnification, x100). (B) Transwell assay examining cell invasion magnification, x100). (C) Apoptotic rate. (D) Western blot analysis of PDK1/AKT/mTOR signaling. Unpaired t-test and two-way ANOVA analysis were used. * $\mathrm{P}<0.05$ vs. control group. PDK1, pyruvate dehydrogenase kinase 1; p-, phosphorylated.

volume and mass of the tumor were also consistent with this hypothesis (Fig. 6B and C).

Curcumol inhibits the development of prostate cancer and the activation of the PDK1/AKT/mTOR signaling pathway via $m i R-9$. To further verify the effect of miR-9 on curcumol in prostate cancer, a series of experimental tests were performed on the removed tumor bodies. RT-qPCR was used to verify the expression level of miR-9 in each group (Fig. 7A). Examination of the gene and protein expression levels revealed that the miR-9 inhibitor could alleviate the inhibition of curcumol on PDK1, p-AKT and p-mTOR expression (Fig. 7B and C). Thus, in vivo, it was hypothesized that the miR-9 inhibitor might reduce the inhibitory effect of curcumol on the PDK1/AKT/mTOR signaling pathway. Ki67 expression (Fig. 7D) indicated the inhibition of curcumol on prostate cancer. Combined with the above experimental results, miR-9 could mediate curcumol to inhibit the development of prostate cancer cells and the $\mathrm{PDK} 1 / \mathrm{AKT} / \mathrm{mTOR}$ pathway, at least in part.

\section{Discussion}

The present study demonstrated that curcumol had no cytotoxicity or side effects on normal prostate cells. The inhibitory 
A

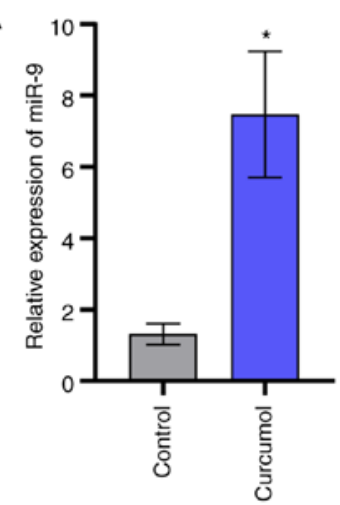

D

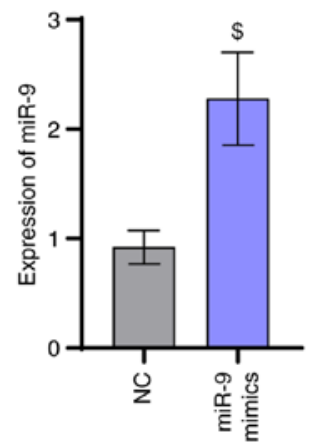

B

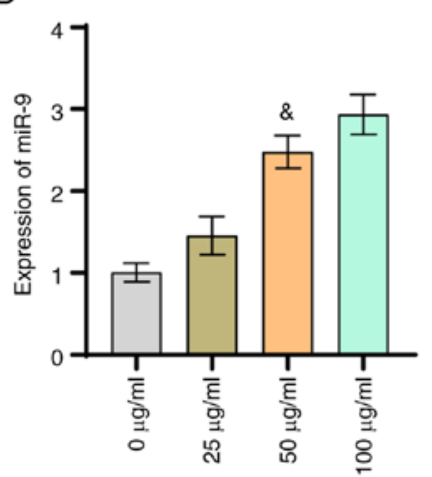

E

wt-PDK1 3'UTR (2163-2170)

5' uauuacaauuuuuuAGCUUAa $3{ }^{\prime}$

| |||| $\mid$

3' ugaaagccaauagaUCGAAAUa $5^{\prime}$

hsa-miR-9-3p

5' uauuacaauuuuuUAUUGCUAa

Mut-PDK1 3'UTR (2163-2170)

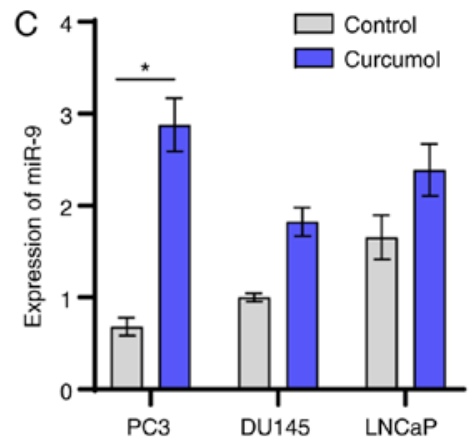

F

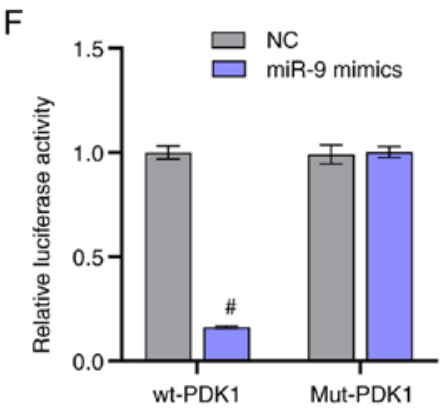

Figure 3. miR-9 targets PDK1. (A) Gene expression level of miR-9. (B) Following treatment with different concentrations of curcumol (0, 25, 50, and $100 \mu \mathrm{g} / \mathrm{ml})$ for $24 \mathrm{~h}$, the expression of miR-9 was determined. (C) Expression of miR-9 in prostate cancer cell lines (PC3, DU145, and LNCaP). (D) Following transfection with NC mimics and miR-9 mimics, the expression of miR-9 was determined. (E) Diagram of PDK1 and miR-9 interactions. (F) Luciferase reporter assay examining miR-9 and PDK1. t-test, one-way ANOVA and two-way ANOVA analysis were used. ${ }^{*} \mathrm{P}<0.05 \mathrm{vs}$. Control group; ${ }^{\&} \mathrm{P}<0.05 \mathrm{vs} .0 \mu \mathrm{g} / \mathrm{ml} ;{ }^{\$} \mathrm{P}<0.05 \mathrm{vs} . \mathrm{NC}$ group; ${ }^{\text {P }<0.05 ~ v s . ~ w t ~+~ N C ~ g r o u p . ~ m i R, ~ m i c r o R N A ; ~ P D K 1, ~ p y r u v a t e ~ d e h y d r o g e n a s e ~ k i n a s e ~ 1 ; ~ N C, ~ n e g a t i v e ~ c o n t r o l ; ~ w t, ~ w i l d-t y p e ; ~ M u t, ~ m u t a n t . ~}$
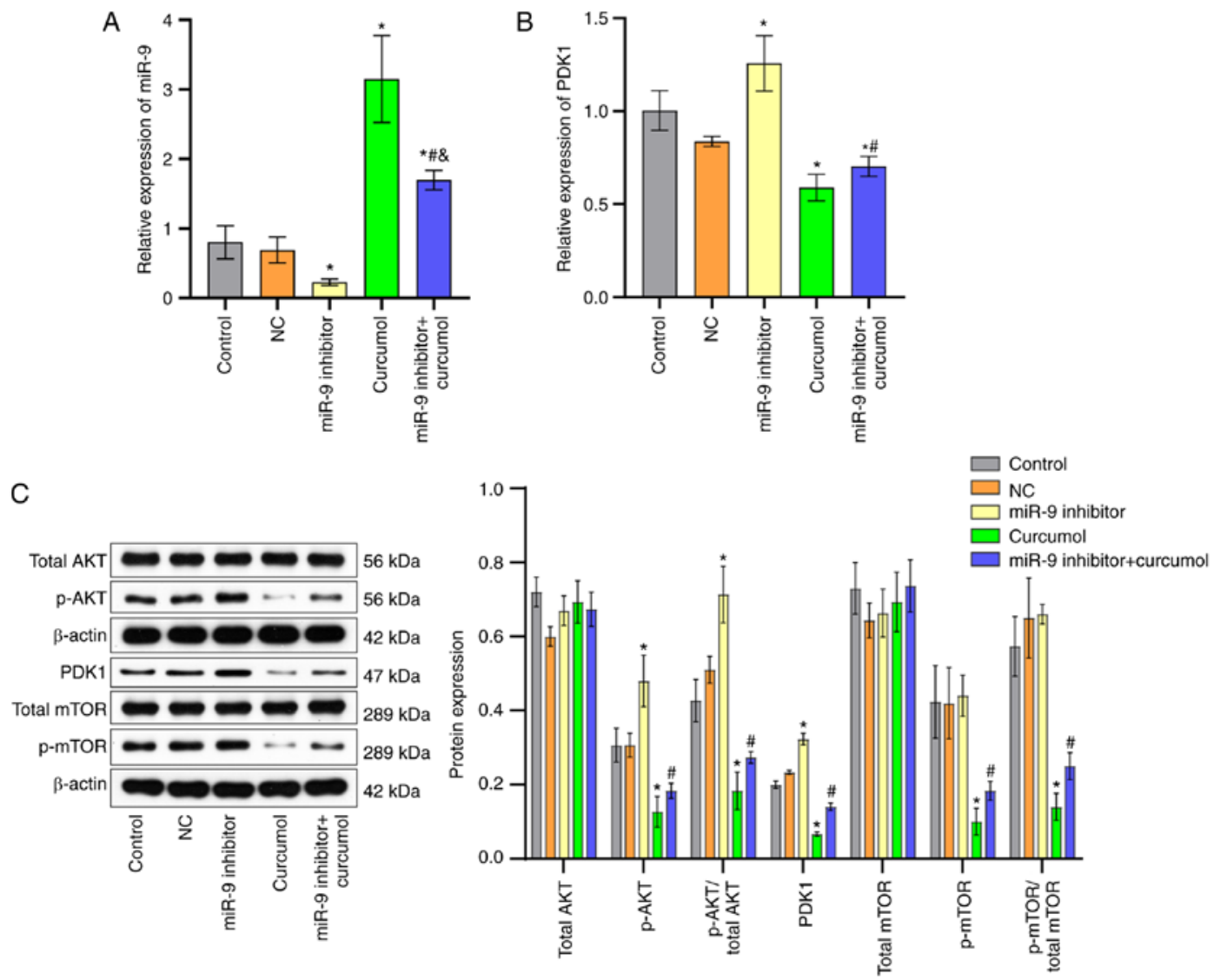

Figure 4. Curcumol regulates the PDK1/AKT/mTOR signaling pathway via miR-9. (A and B) Reverse transcription-quantitative PCR results. (C) Western blotting results. One-way ANOVA and two-way ANOVA analysis were used. ${ }^{*} \mathrm{P}<0.05$ vs. control group; ${ }^{~} \mathrm{P}<0.05$ vs. miR-9 inhibitor group; ${ }^{\circledR} \mathrm{P}<0.05$ vs. Curcumol group. PDK1, pyruvate dehydrogenase kinase 1; miR, microRNA; p-, phosphorylated. 
A
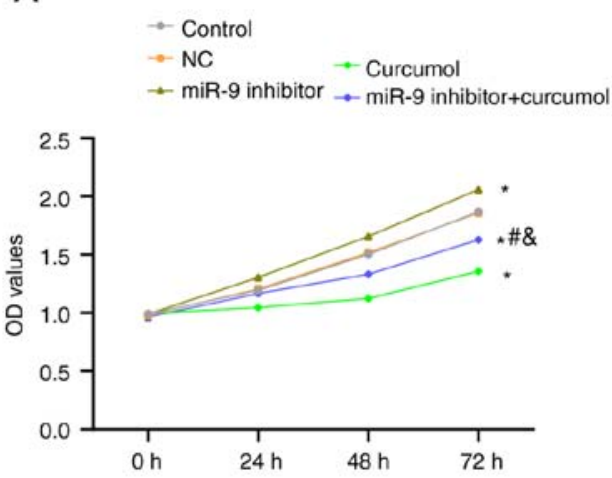

B

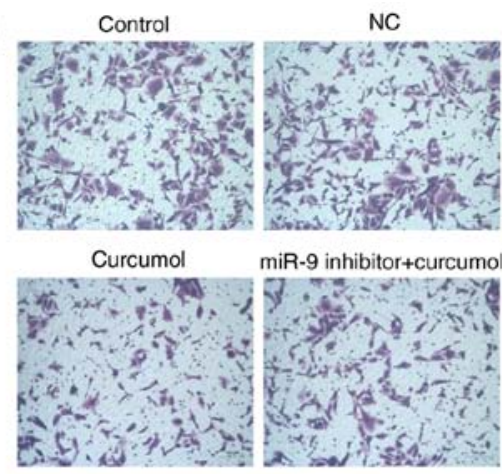

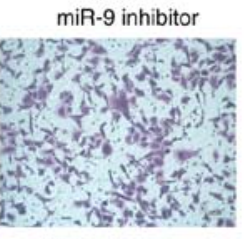

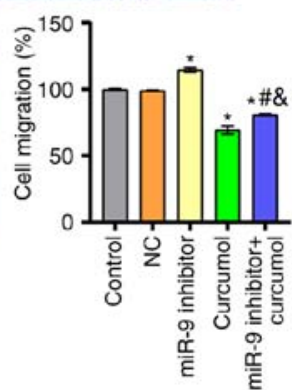

C
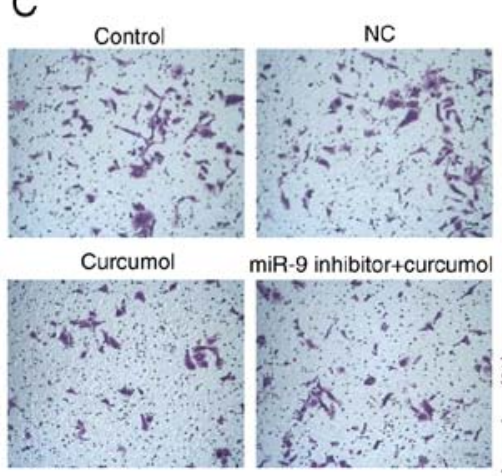

miR-9 inhibitor
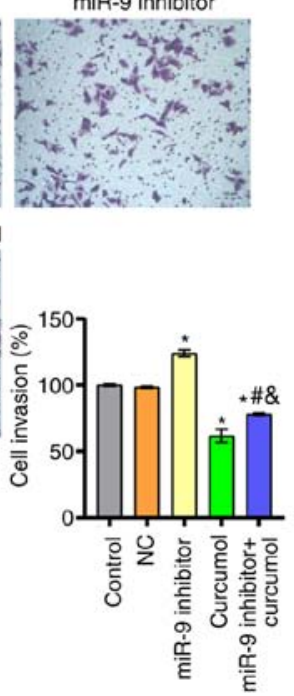

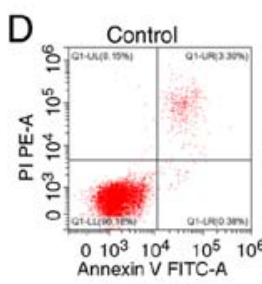

Curcumol

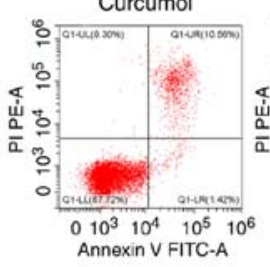

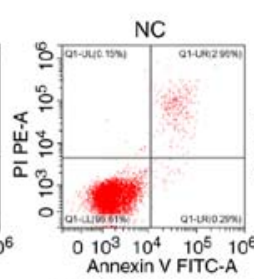

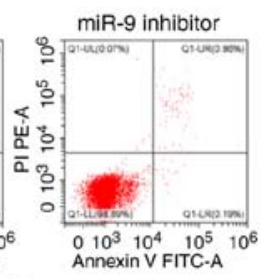

miR-9 inhibitor+curcumol

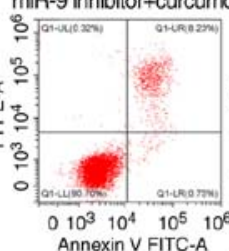

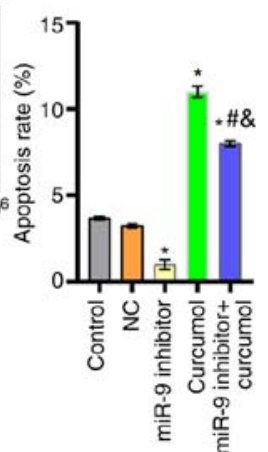

Figure 5. Curcumol affects the activity of PC3 cells via miR-9. (A) Cell Counting Kit-8 results. (B) Transwell detection of cell migration magnification, x100). (C) Transwell detection of cell invasion magnification, x100). (D) Apoptosis rate. One-way ANOVA and two-way ANOVA analysis were used. "P<0.05 vs. control group; ${ }^{\#} \mathrm{P}<0.05$ vs. miR-9 inhibitor group; ${ }^{\circledR} \mathrm{P}<0.05$ vs. Curcumol group. PDK1, pyruvate dehydrogenase kinase 1 ; miR, microRNA; NC, negative control.

effect on prostate cancer cells was clear. PC3, LNCaP and DU145 cells demonstrated different drug sensitivities to curcumol. In a previous study examining the sensitivity of prostate cancer cells to docetaxel, it was reported that rapamycin could resist docetaxel-induced apoptosis and that rapamycin can induce autophagy in PC3 cells but not in DU145 cells (18). Pickard et al (19) also demonstrated that docetaxel produced significant toxicity in PC3 cells, but no toxicity was observed in LNCaP cells. The studies above reveal that PC3 cell lines are more sensitive to drug toxicity compared with LNCaP and DU145 cell lines. This was consistent with the findings of the present study that PC3 cells were more sensitive to curcumol than LNCaP and DU145 cell lines. Combined with the expression of miR-9 in different cell lines, it is reasonable to hypothesize that the sensitivity of these three prostate cancer cell lines (PC3, LNCaP and DU145 cell lines) to curcumol is different, which may be mediated by miR-9. However, the specific mechanism by which curcumol regulates miR-9 remains to be elucidated.

Curcumol, a naturally extracted drug, has been used in the study of a variety of types of cancer. In bladder cancer cells, curcumol can affect cell proliferation and apoptosis by targeting enhancer of zeste homolog 2 and regulating the mitochondrial apoptosis pathway (10). Curcumol can affect cell proliferation by increasing reactive oxygen species, decreasing mitochondrial membrane potential and downregulating isocitrate dehydrogenase 1 in gastric adenocarcinoma (20). In hepatocellular carcinoma cells, curcumol inhibits the expression of programmed cell death-ligand 1 through hypoxia-inducible factor- $1 \alpha$ and signal transducer and activator of transcription 3 signaling pathways, restoring the tumor-killing ability of cytotoxic T cells (9). All these suggested that curcumol has a certain anti-tumor activity. The regulatory pathway of curcumol may be different in different cell types. In addition, curcumol may be a developmental neurotoxic substance that may affect the neurites' growth via the neural cell adhesion molecule/focal adhesion kinase signaling pathway (21). Wang et al (22) also reported that curcumol had a certain inhibitory effect on $\mathrm{CD}^{+} \mathrm{T}$ cells. Collectively, these results suggest that curcumol may affect the body's anti-tumor immune regulation in vivo and hinder its anti-tumor activity. Notably, a previous study has shown 

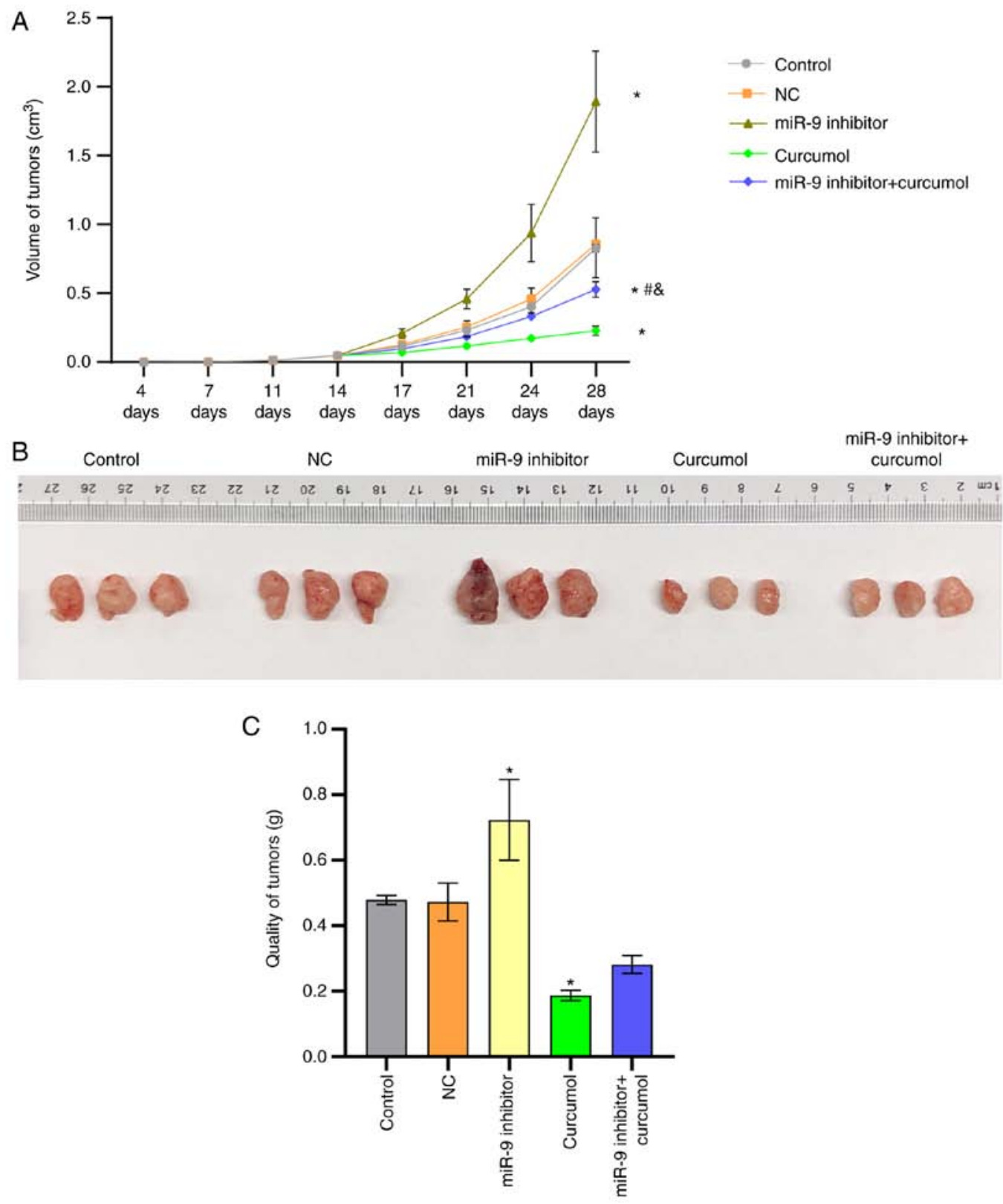

Figure 6. Curcumol inhibits tumor growth in mice. (A) Tumor volume. (B) Images of the tumor. (C) Mass of tumor. One-way ANOVA and two-way ANOVA analysis were used. ${ }^{*} \mathrm{P}<0.05$ vs. control group; ${ }^{\#} \mathrm{P}<0.05$ vs. miR-9 inhibitor group; ${ }^{~} \mathrm{P}<0.05$ vs. Curcumol group. PDK1, pyruvate dehydrogenase kinase 1 ; miR, microRNA.

that curcumol can induce cancer cell cycle arrest by inhibiting the insulin-like growth factor 1 receptor/PI3K/AKT pathway (23). Curcumol inhibits the development of melanoma (17) and colorectal cancer (14) through PI3K/AKT pathway. All these studies suggest that curcumol may affect tumor development through the PI3K/AKT pathway, at least in part. The results of the present study also demonstrated that curcumol inhibited the development of prostate cancer and regulated the $\mathrm{PDK} 1 / \mathrm{AKT} / \mathrm{mTOR}$ signaling pathway. Thus, the PDK1/AKT/mTOR signaling pathway might be a possible pathway for curcumol to affect the development of prostate cancer.

The present study further investigated the internal regulatory pathways of curcumol inhibition of PC3 cell activity. The results indicated that curcumol could significantly upregulate the expression level of miR-9. It has been revealed that miR-9 was differentially expressed in young and elderly patients with prostate cancer (24). Thus, miR-9 may be involved in the development of prostate cancer. A previous study has shown that miR-9 can promote the development of multiple myeloma by regulating the tripartite motif-containing protein $56 / \mathrm{NF}-\kappa \mathrm{B}$ pathway (25). miR-9 can promote cell migration and invasion of synovial osteosarcoma by directly targeting E-cadherin (26). miR-9 can induce angiogenesis by targeting sphingosine-1-phosphate receptor 1 (27). All these results suggest that miR-9 may be an oncogene. By contrast, the current study found that in PC3 cells, curcumol could regulate the downstream signaling pathway by upregulating the expression of miR-9, thus affecting the proliferation, migration, invasion and apoptosis of PC3 cells. Some studies have shown that miR-9 can inhibit cancer. Wang et al (28) also reported that miR-9 could inhibit colorectal cancer cell invasion and EMT by targeting forkhead box P2. miR-9 could inhibit the proliferation and invasion of pancreatic cancer 


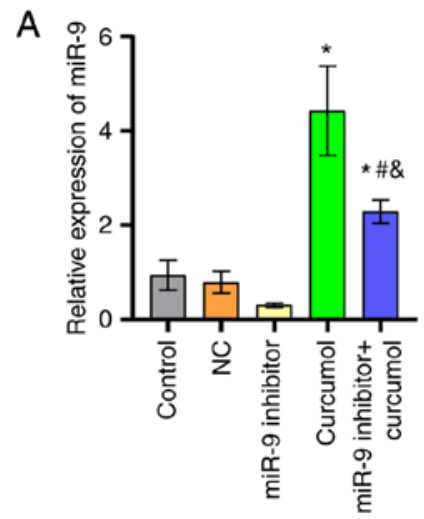

B
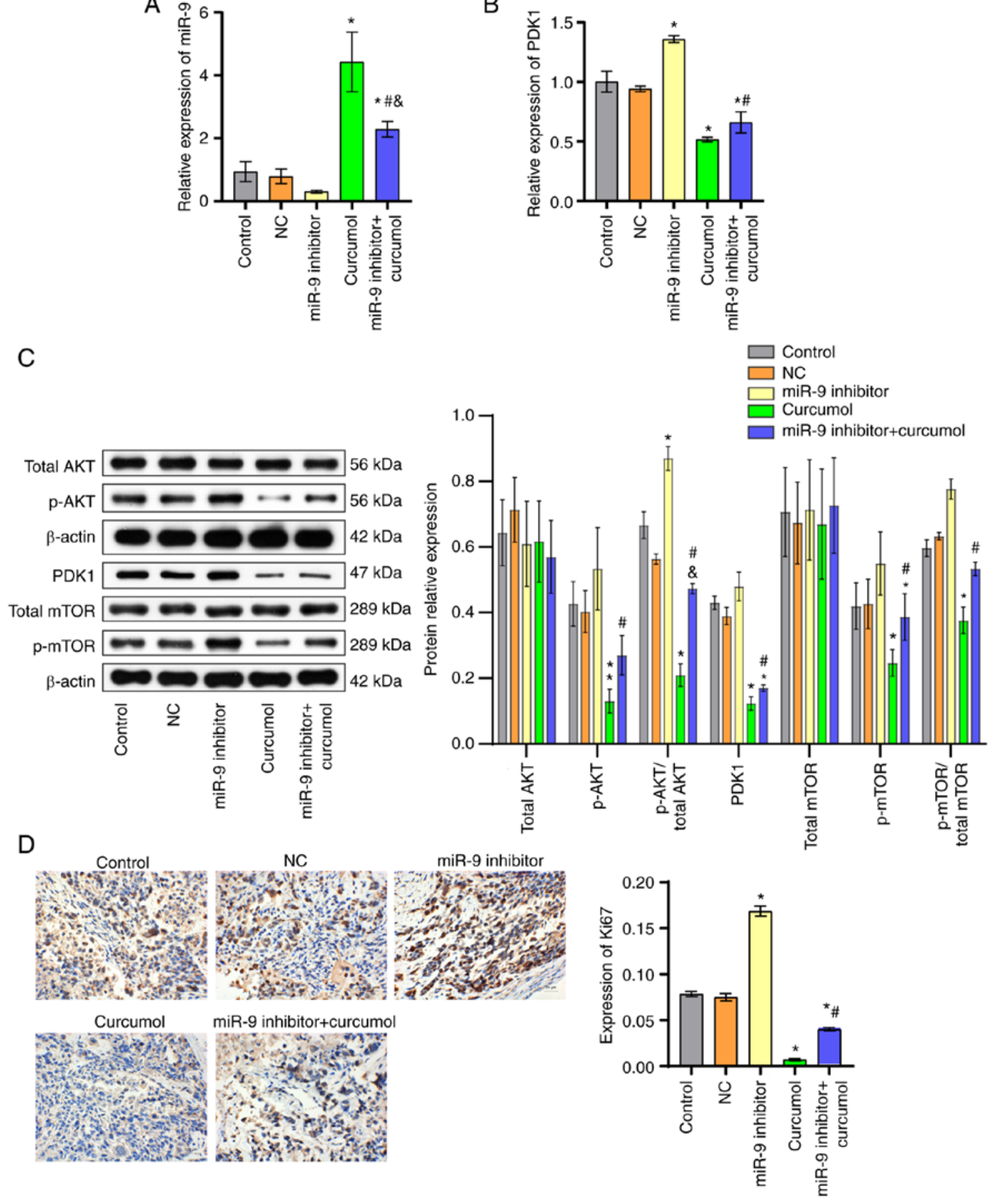

Figure 7. Curcumol inhibits the development of prostate cancer via miR-9. (A and B) Reverse transcription-quantitative PCR results. (C) Western blotting results. (D) Immunohistochemistry results (magnification, $\mathrm{x} 400$ ). One-way ANOVA and two-way ANOVA analysis were used. " $\mathrm{P}<0.05$ vs. control group; ${ }^{\text {"P }}<<0.05$ vs. miR-9 inhibitor group; ${ }^{\text {}} \mathrm{P}<0.05$ vs. Curcumol group. miR, microRNA; PDK1, pyruvate dehydrogenase kinase 1; $\mathrm{p}$-, phosphorylated.

cells by targeting glutamate oxaloacetate transaminase 1 (29). miR-9 in exosomes can inhibit angiogenesis in nasopharyngeal carcinoma by targeting Midkine (30). These findings support the conclusion of the current study that miR-9 could also act as a tumor suppressor gene to alleviate tumor progression. Therefore, it was concluded that the internal regulatory mechanism of miR-9 is different in different environments and that its role will also be different.

The in vivo and in vitro results demonstrated that miR-9 at least partly mediated the inhibitory effect of curcumol on prostate cancer. Following prediction analysis using the
TargetScan website and luciferase reporter assays, it was identified that miR-9 could directly target PDK1. The present study found that the expression level of PDK1 in PC 3 cells was significantly altered after curcumol treatment. In glioblastoma, it has been reported that activation of the PDK1/c-Jun pathway can induce EMT and promote the proliferation and invasion of tumor cells (31). In a related study of hypopharyngeal cancer, PDK1 has been shown to induce EMT and promote cancer cell invasion (32). In ovarian cancer, PDK1 can regulate tumor-mesothelial adhesion and angiogenesis, as well as promoting cancer cell invasion (33). However, reduced PDK1 
expression can inhibit the proliferation, migration and EMT of renal cancer cells (34). These findings were similar to the results of the current study, that the expression level of PDK1 in cancer cells was higher compared with that in the curcumol treatment group. By contrast, PDK1 acts as an independent driver of the PI3K/AKT/mTOR signaling pathway (35). This further confirms the hypothesis of the present study, that curcumol regulated the PDK1/AKT/mTOR signaling pathway via miR-9 and affected the progression of prostate cancer.

Considering the limited experimental conditions, there remain several deficiencies in the current study. Due to limited time and funding availability, it did not include the pharmacokinetics of non-injected curcumol in humans. At present, the specific mechanism of the resistance of different prostate cancer cell lines to curcumol is unable to be fully determined due to a shortage of funds. The mechanism of miR-9 upregulation caused by curcumol therapy has not been fully elucidated due to limitations of the experimental conditions. The question of whether inhibition of the PDK1/AKT/mTOR signaling pathway is the cause of inhibition of curcumol-mediated prostate cancer cell proliferation has not yet been completely determined. These unanswered questions will be the focus of future research. Future studies will further examine the mechanism of action and drug resistance of curcumol in prostate cancer cells. The regulatory mechanism between curcumol and miR-9 will also be further studied, as will the role of the PDK1/AKT/mTOR signaling pathway in the influence of curcumol on the progression of prostate cancer cells. The pharmacokinetics and bioavailability data of curcumol in the human body also will be further collect.

In conclusion, the present study demonstrated that curcumol could upregulate the expression level of miR-9 and inhibit the activity of PC3 cells. It was identified that miR-9 could directly target PDK1 and regulate the PDK1/AKT/mTOR signaling pathway. Therefore, curcumol regulated the PDK1/AKT/mTOR signaling pathway and inhibited the development of prostate cancer through miR-9. These findings provided a reliable scientific basis for the treatment of prostate cancer with curcumol.

\section{Acknowledgements}

Not applicable.

\section{Funding}

This work was supported by the National Natural Science Foundation (grant no. 81774324), and the Postgraduate Innovation Project of Hunan Province (grant no. CX2018B463).

\section{Availability of data and materials}

The analyzed datasets generated during the current study are available from the corresponding author upon reasonable request.

\section{Authors' contributions}

WS and WX conceived and designed the experiments. JD and XY performed the experiments. LL analyzed the data.
LL and YW confirm the authenticity of all the raw data. YW and $\mathrm{QH}$ drafted the manuscript and revised it critically for important intellectual content. WS, WX, and QH agreed to be accountable for all aspects of the present study in ensuring that questions related to the accuracy or integrity of any part of the present study are appropriately investigated and resolved. All authors approved the final manuscript.

\section{Ethics approval and consent to participate}

All of experiments were conducted in accordance with the recommendation and approval of Animal Welfare Committee of Hunan University of Chinese Medicine (approval number: 2019-0019).

\section{Patient consent for publication}

Not applicable.

\section{Competing interests}

The authors declare that they have no competing interests.

\section{References}

1. Bray F, Ferlay J, Soerjomataram I, Siegel RL, Torre LA and Jemal A: Global cancer statistics 2018: GLOBOCAN estimates of incidence and mortality worldwide for 36 cancers in 185 countries. CA Cancer J Clin 68: 394-424, 2018.

2. Sebesta EM and Anderson CB: The surgical management of prostate cancer. Semin Oncol 44: 347-357, 2017.

3. Cordes LM, Gulley JL and Madan RA: The evolving role of immunotherapy in prostate cancer. Curr Opin Oncol 28: 232-240, 2016.

4. Gourdin T: Optimization of therapies for men with advanced prostate cancer: A review of recent developments with a look toward the future. Curr Opin Oncol 31: 188-193, 2019.

5. Wu H, You L, Li Y, Zhao Z, Shi G, Chen Z, Wang Z, Li X, Du S, Ye W, et al: Loss of a negative feedback loop between IRF8 and AR promotes prostate cancer growth and enzalutamide resistance. Cancer Res 80: 2927-2939, 2020.

6. Wei W, Rasul A, Sadiqa A, Sarfraz I, Hussain G, Nageen B, Liu X, Watanabe N, Selamoglu Z, Ali M, et al: Curcumol: From plant roots to cancer roots. Int J Biol Sci 15: 1600-1609, 2019.

7. Li YQ, Li GZ, Dong Y, Ma X, Dong HJ, Wu QQ and Zhao WJ: Orobanone analogues from acid-promoted aromatization rearrangement of curcumol inhibit hypoxia-inducible factor-1 (HIF-1) in cell-based reporter assays. Bioorg Chem 85: 357-363, 2019.

8. Li G, Lin J, Peng Y, Qin K, Wen L, Zhao T and Feng Q: Curcumol may reverse early and advanced liver fibrogenesis through downregulating the uPA/uPAR pathway. Phytother Res 34: 1421-1435, 2020.

9. Zuo HX, Jin Y, Wang Z, Li MY, Zhang ZH, Wang JY, Xing Y, $\mathrm{Ri} \mathrm{MH}$, Jin $\mathrm{CH}$, Xu GH, et al: Curcumol inhibits the expression of programmed cell death-ligand 1 through crosstalk between hypoxia-inducible factor-1 $\alpha$ and STAT3 (T705) signaling pathways in hepatic cancer. J Ethnopharmacol 257: 112835, 2020.

10. Zhou L, Wei E, Zhou B, Bi G, Gao L, Zhang T, Huang J, Wei Y and Ge B: Anti-proliferative benefit of curcumol on human bladder cancer cells via inactivating EZH2 effector. Biomed Pharmacother 104: 798-805, 2018.

11. Zhang W, Wang Z and Chen T: Curcumol induces apoptosis via caspases-independent mitochondrial pathway in human lung adenocarcinoma ASTC-a-1 cells. Med Oncol 28: 307-314, 2011.

12. Wang G, Dong Y and Liu H: Curcumol enhances the anti-tumor effects of metformin via suppressing epithelial-mesenchymal transition in triple-negative breast cancer. Ann Transl Med 8: 946, 2020.

13. Zeng C, Fan D, Xu Y, Li X, Yuan J, Yang Q, Zhou X, Lu J, Zhang C, Han J, et al: Curcumol enhances the sensitivity of doxorubicin in triple-negative breast cancer via regulating the miR-181b-2-3p-ABCC3 axis. Biochem Pharmacol 174: 113795, 2020. 
14. Liu H, Wang J, Tao Y, Li X, Qin J, Bai Z, Chi B, Yan W and Chen X: Curcumol inhibits colorectal cancer proliferation by targeting miR-21 and modulated PTEN/PI3K/Akt pathways. Life Sci 221: 354-361, 2019

15. Livak KJ and Schmittgen TD: Analysis of relative gene expression data using real-time quantitative PCR and the 2(-Delta Delta $\mathrm{C}(\mathrm{T}))$ method. Methods 25: 402-408, 2001.

16. Yang C, Zhang JJ, Zhang XP, Xiao R and Li PG: Sporamin suppresses growth of xenografted colorectal carcinoma in athymic BALB/c mice by inhibiting liver $\beta$-catenin and vascular endothelial growth factor expression. World J Gastroenterol 25: 3196-3206, 2019.

17. Ning N, Liu S, Liu X, Tian Z, Jiang Y, Yu N, Tan B, Feng H, Feng $X$ and Zou L: Curcumol inhibits the proliferation and metastasis of melanoma via the miR-152-3p/PI3K/AKT and ERK/NF- $\kappa B$ signaling pathways. J Cancer 11: 1679-1692, 2020.

18. Cristofani R, Montagnani Marelli M, Cicardi ME, Fontana F Marzagalli M,Limonta P, Poletti A and Moretti RM: Dual role of autophagy on docetaxel-sensitivity in prostate cancer cells. Cell Death Dis 9: 889, 2018

19. Pickard RD, Spencer BH, McFarland AJ, Bernaitis N, Davey AK, Perkins AV, Chess-Williams R, McDermott CM, Forbes A, Christie D and Anoopkumar-Dukie S: Paradoxical effects of the autophagy inhibitor 3-methyladenine on docetaxel-induced toxicity in PC-3 and LNCaP prostate cancer cells. Naunyn Schmiedebergs Arch Pharmacol 388: 793-799, 2015.

20. Zang S, Tang Q, Dong F, Liu H, Li L, Guo F, Pan X, Lin H, Zeng W, Cai Z, et al: Curcumol inhibits the proliferation of gastric adenocarcinoma MGC-803 cells via downregulation of IDH1. Oncol Rep 38: 3583-3591, 2017.

21. Yu C, Sun X and Niu Y: An investigation of the developmental neurotoxic potential of curcumol in PC12 cells. Toxicol Mech Methods 26: 635-643, 2016.

22. Wang H, Wang Y, Jiang X, Wang Z, Zhong B and Fang Y: The molecular mechanism of curcumol on inducing cell growth arrest and apoptosis in Jurkat cells, a model of CD4 ${ }^{+} \mathrm{T}$ cells. Int Immunopharmacol 21: 375-382, 2014.

23. Li X, Liu H, Wang J, Qin J, Bai Z, Chi B, Yan W and Chen X: Curcumol induces cell cycle arrest and apoptosis by inhibiting IGF-1R/PI3K/Akt signaling pathway in human nasopharyngeal carcinoma CNE-2 cells. Phytother Res 32: 2214-2225, 2018.

24. Valera VA, Parra-Medina R, Walter BA, Pinto P and Merino MJ: microRNA expression profiling in young prostate cancer patients. J Cancer 11: 4106-4114, 2020.

25. Huang G, Liu X, Zhao X, Zhao J, Hao J, Ren J and Chen Y: miR-9 promotes multiple myeloma progression by regulating TRIM56/NF-кB pathway. Cell Biol Int 43: 1223-1233, 2019.
26. Xu XZ, Li XA, Luo Y, Liu JF, Wu HW and Huang G: miR-9 promotes synovial sarcoma cell migration and invasion by directly targeting CDH1. Int J Biochem Cell Biol 112: 61-71, 2019.

27. Yao X, Xie L and Zeng Y: miR-9 promotes angiogenesis via targeting on sphingosine-1-phosphate receptor 1. Front Cell Dev Biol 8: 755, 2020.

28. Wang WX, Yu HL and Liu X: miR-9-5p suppresses cell metastasis and epithelial-mesenchymal transition through targeting FOXP2 and predicts prognosis of colorectal carcinoma. Eur Rev Med Pharmacol Sci 23: 6467-6477, 2019.

29. Wang J, Wang B, Ren H and Chen W: miR-9-5p inhibits pancreatic cancer cell proliferation, invasion and glutamine metabolism by targeting GOT1. Biochem Biophys Res Commun 509: 241-248, 2019.

30. Lu J, Liu QH, Wang F, Tan JJ, Deng YQ, Peng XH, Liu X, Zhang B, Xu X and Li XP: Exosomal miR-9 inhibits angiogenesis by targeting MDK and regulating PDK/AKT pathway in nasopharyngeal carcinoma. J Exp Clin Cancer Res 37: 147, 2018

31. Luo D, Xu X, Li J, Chen C, Chen W, Wang F, Xie Y and Li F: The PDK1/c-Jun pathway activated by TGF- $\beta$ induces EMT and promotes proliferation and invasion in human glioblastoma. Int J Oncol 53: 2067-2080, 2018.

32. Jing P, Zhou S, Xu P, Cui P, Liu X, Liu X, Liu X, Wang H and $\mathrm{Xu}$ W: PDK1 promotes metastasis by inducing epithelialmesenchymal transition in hypopharyngeal carcinoma via the Notch1 signaling pathway. Exp Cell Res 386: 111746, 2020.

33. Siu MK, Jiang YX, Wang JJ, Leung TH, Ngu SF, Cheung AN, Ngan HY and Chan KK: PDK1 promotes ovarian cancer metastasis by modulating tumor-mesothelial adhesion, invasion, and angiogenesis via $\alpha 5 \beta 1$ integrin and JNK/IL-8 signaling. Oncogenesis 9: 24, 2020.

34. Zhou WM, Wu GL, Huang J, Li JG, Hao C, He QM, Chen XD, Wang GX and Tu XH: Low expression of PDK1 inhibits renal cell carcinoma cell proliferation, migration, invasion and epithelial mesenchymal transition through inhibition of the PI3K-PDK1-Akt pathway. Cell Signal 56: 1-14, 2019.

35. Bamodu OA, Chang HL, Ong JR, Lee WH, Yeh CT and Tsai JT: Elevated PDK1 expression drives PI3K/AKT/MTOR signaling promotes radiation-resistant and dedifferentiated phenotype of hepatocellular carcinoma. Cells 9: 746, 2020.

This work is licensed under a Creative Commons Attribution-NonCommercial-NoDerivatives 4.0 International (CC BY-NC-ND 4.0) License. 